\title{
Food Behavior Correlated with Lifestyle Pattern and Societal Influences in a Romanian Students Population. Part I: Eating General Habits
}

\section{Iuliana Vintila}

Food Science and Engineering, Biotechnology and Aquaculture Department, "Dunarea de Jos" University, Galati, Romania.

Email: vintilaiuliana@yahoo.com

Received May $16^{\text {th }}, 2013$; revised June $16^{\text {th }}, 2013$; accepted June $24^{\text {th }}, 2013$

Copyright (C) 2013 Iuliana Vintila. This is an open access article distributed under the Creative Commons Attribution License, which permits unrestricted use, distribution, and reproduction in any medium, provided the original work is properly cited.

\begin{abstract}
Input data from Students Food Behavior, Preference and Lifestyle Questionnaire conducted with 376 students from University "Dunarea de Jos" Galati (UDJG) were analyzed from socio-demographic criteria. The sample socio-demoraphic characteristics of the student population were investigated beside the general food \& eating habits by gender. In the current study, most than three quart of students $(76.06 \%$ ) was of correct (normal) weight. Nearly $65.15 \%$ of the students reported having regular daily breakfast. The strongest correlation of having breakfast habit is show with the regular meal behaviour $[\mathrm{r}(3,4)=0.242]$ and regular meals were associated with reduced trends for $\mathrm{BMI}[\mathrm{r}(4,2)=-0.055]$.
\end{abstract}

Keywords: Food Habits; Eating Pattern; Body Mass Index (BMI)

\section{Introduction}

The evident decreasing of the immune-physical status of the students associated with serious health problem and decreasing of academic interest \& performance became a crude reality in last decades due to societal and moral values change. The fashionable contamination from the occidental eating style is a reality in the past decades and the traditional influence of family or school is minimizing and percept as old tasting.

Also, international studies have indicated that many adolescents find it difficult to follow healthful eating recommendations and make finally the easy choice of accessible and convenience fast-food items [1,2].

The Ministry of Public Health in Romania is responsible for the health policy, regulations, health programs, and investments in public establishments. The main regulatory law for healthy eating in schools is $128 / 2008$, Law about the interdiction of fast-food products in pre-universitary schools. In the University area, there is no legal regulation in providing catering services, in part, because of the university autonomy [3].

The objective of Part I research study were to investigate the socio-demographic characteristics of a Romanian student population $(\mathrm{N}=376)$ beside the general food \& eating habits by gender.

\section{Methods of Conducting Social Investigation}

376 UDJG students (177 boys and 199 girls) in the age range of $20-24$ years random selected, complete the questionnaire concerning activities related to eating behavior and lifestyle, societal influences, self-appreciation of food behavior health \& emotional impact and change intention. The survey was conducted during the period December 2010-January 2011 and the participation was not compulsory. The students were assured of complete anonymity. The volunteered youth complete the survey in a time between 30 and $40 \mathrm{~min}$. A general characterization of the investigated group was socio-demographic and anthropometric: age, gender, height, weight, geographic origins, international mobility and accessibility of healthy food.

\subsection{Questionnaire}

A Food Behavior and Lifestyle Questionnaire (FBLQ) were constructed to assess food behavior integrated in a lifestyle with influences, impact and intention of food behavior change variables. The questionnaire divided in two parts, a quantitative part with 44 questions and a second qualitative part with other 10 questions consisting in perception $\&$ attitude variables. 
Lifestyle variables, food behaviors, impact \& change intention and societal influences were assessed with the following instruments: 1) a 5-point Likert scale ("none, never" to "very slight, a little", "medium", "important", "high"; 2) overall food behavior/lifestyle rated with a bipolar assessment scale (negative response/positive response).

BMI was calculated using the formula BMI $=$ weight $(\mathrm{kg}) /$ height $(\mathrm{m})^{2}$ from self-reported heights and weights. The classification from BMI were realised in underweight $(\mathrm{BMI}<18)$, normal weight $(\mathrm{BMI}=18-25)$, overweight $(\mathrm{BMI}=25-30)$ and obesity (grade I BMI $=30-35$, grade II BMI $=35-40$, grade III BMI $>40$ ).

The positive or healthy dietary habits were asses with vegetable and fish daily consummation and the negative or unhealthy dietary habits with the red meat, pizza, carbonated drinks, alcohol and coffee consummation. The references of consummation were established according with $\mathrm{FAO} / \mathrm{OMS}$ recommendation.

The eating patterns variables were considered as followings: breakfast, regular meals, daily energy intake, number of family meals, eating-out meals, canteen meals, individual preparation meals, meal alone.

\subsection{Statistical Analysis}

The data collected was processed using a Statistical Package for the Social Sciences SPSS Statistics 17.0 (SPSS,
Inc. Chicago, IL) and Statistical Analysis System 8.0 for Windows (SAS Institute, Cary, NC, 1999).

\section{Results}

\subsection{Sample Characteristics}

The socio-demographic characteristics of the investigated sample were presented in Table 1.

Boys mean age was not significantly different from girls mean age from the same year of study (21.57 years and 21.25 years respectively, $p>0.05$ ). The students sample is dominated by the first and second year of the bachelor stage which is normal in the general distribution of student's population per years. The SD value is 1.31 in boy's group case and 1.22 in girl's case, due to the fact that the investigation protocol includes students from all license level (bachelor level).

Mean BMI was significantly lower for girls group than in boy's case $\left(20.85 \mathrm{~kg} / \mathrm{m}^{2}\right.$ vs. $23.75 \mathrm{~kg} / \mathrm{m}^{2}$, respectively, $p<0.05$ ). In most cases, we identify a body mass control more strict for the girl's student and a restricted diet self-imposed. BMI ranged from 12.4 to $27.3 \mathrm{~kg} / \mathrm{m}^{2}$ in girls and from $12.2-26.3 \mathrm{~kg} / \mathrm{m}^{2}$ in boys.

The mean BMI is 23.75 in male student's case and 20.85 in girl's group case, with a SD of 3.45 and 2.74, respectively. The BMI distribution from reported height and weight values were shown in Table 2.

Table 1. General socio-demographic characterization of the students population $(\mathrm{N}=376)$.

\begin{tabular}{|c|c|c|c|c|c|}
\hline & Socio-demographic characteristic & Min. & Max. & Mean & SD \\
\hline \multirow{4}{*}{ TOTAL } & Age & 20 & 24 & 21.41 & 1.275 \\
\hline & Personal revenue/month (Euro) & 0 & 380.9 & 91.2 & 60.43 \\
\hline & Body mass index (BMI) & 14 & 42 & 22.21 & 3.42 \\
\hline & Family revenue/month & 83.3 & 1904.7 & 486.1 & 244.8 \\
\hline \multirow{2}{*}{$N=376$} & Family extent & 1 & 9 & 3.63 & 1.07 \\
\hline & International mobility (number of visited countries) & 0 & 9 & 1.19 & 1.67 \\
\hline \multirow{6}{*}{$\begin{array}{c}\text { BOYS } \\
\mathrm{N}_{\mathrm{B}}=177\end{array}$} & Age & 20 & 24 & 21.57 & 1.31 \\
\hline & Personal revenue/month (Euro) & 11.9 & 380.9 & 105.5 & 68.6 \\
\hline & Body mass index (BMI) & 16.97 & 42.48 & 23.75 & 3.45 \\
\hline & Family revenue/month & 83.3 & 1905 & 508.1 & 256.1 \\
\hline & ASP/day (Euro) & 0 & 20.8 & 3.99 & 2.1 \\
\hline & International mobility (number of visited countries) & 0 & 9 & 1.34 & 1.71 \\
\hline \multirow{4}{*}{ GIRLS N $\mathrm{F}_{\mathrm{F}}=199$} & Age & 20 & 24 & 21.25 & 1.22 \\
\hline & Personal revenue/month (Euro) & 0 & 357.1 & 77.8 & 48.5 \\
\hline & Body mass index (BMI) & 13.84 & 34.35 & 20.85 & 2.74 \\
\hline & Family revenue/month & 83.3 & 1904.7 & 453 & 232.6 \\
\hline \multirow{3}{*}{$\begin{array}{c}\text { LS } \\
\mathrm{N} \mathrm{F}=199\end{array}$} & Family extent & 1 & 9 & 3.71 & 1.12 \\
\hline & ASP/day (Euro) & 0 & 14.3 & 3.5 & 2.5 \\
\hline & International mobility (number of visited countries) & 0 & 9 & 1.06 & 1.62 \\
\hline
\end{tabular}


Table 2. Socio-demographic characteristics depending on sample gender $(\mathrm{N}=376)$.

\begin{tabular}{|c|c|c|c|c|}
\hline Socio-demographic characteristics & Total & Boys $(\%)$ & Girls (\%) & Statistic values chi-square/df/p \\
\hline Gender & 100 & 47.07 & 52.93 & - \\
\hline \multicolumn{5}{|c|}{ Marital status } \\
\hline Married & 1.32 & 1.12 & 1.5 & \multirow{2}{*}{$0.34 / 1 / 0.56$} \\
\hline Single & 98.88 & 98.88 & 98.5 & \\
\hline \multicolumn{5}{|c|}{ Geographic origin } \\
\hline Moldavia & 42.02 & 34.46 & 48.74 & \multirow{3}{*}{$7.82 / 5 / 0.16$} \\
\hline South & 39.62 & 44.06 & 35.67 & \\
\hline East & 10.37 & 12.42 & 8.54 & \\
\hline \multicolumn{5}{|c|}{ BMI } \\
\hline Underweight & 6.38 & 2.25 & 10.06 & \multirow{6}{*}{$2.67 / 2.46 / 0.16$} \\
\hline Normal Weight & 76.06 & 68.36 & 82.91 & \\
\hline Overweight & 15.15 & 24.85 & 6.53 & \\
\hline Obesity grade I & 2.15 & 3.95 & 0.50 & \\
\hline Obesity grade II & 0 & 0 & 0 & \\
\hline Obesity grade III & 0.26 & 0.59 & 0 & \\
\hline \multicolumn{5}{|c|}{ International mobility } \\
\hline None foreign country visited & 6.38 & 42.37 & 53.26 & \multirow{3}{*}{$11.44 / 9 / 0.247$} \\
\hline 1-2 visited countries & 32.97 & 35.59 & 30.65 & \\
\hline More than 2 visited countries & 10.37 & 22.04 & 16.09 & \\
\hline \multicolumn{5}{|c|}{ Healthy food accessibility (in financial way) } \\
\hline Low & 49.46 & 51.97 & 47.24 & \multirow{2}{*}{$14.16 / 15 / 0.51$} \\
\hline High & 50.54 & 48.03 & 52.76 & \\
\hline
\end{tabular}

About $6.38 \%$ of the students were under normal weight, most of them were girls. Most students (76.6\%) were of the correct weight. A significant percentage $(15.15 \%)$ was overweight, $2.15 \%$ show the characteristic BMI for grade I obesity and a boy is in morbid obesity stage.

The personal revenue is raported as academic specific grant (social or for academic performance) and the other constant money inputs from jobs, familiy or friends. The mean personal revenue is 91.20 Euros in a month. The family revenue does not include the student personal revenue, only money inputs from the parents and constant other family providers were considered. The family revenue is highly polarisated in a range between 83.3 and 1905 Euro for a number of family member of 3.63 in medium case. In mean per total sample, $21.7 \%$ from family revenue is transfered to the student. The daily average spend power (ASP) as personal daily spend on food (not provided by the familiy) is 3.74 euro, slighly increase in case of male students (3.99 euros).

The overall influence generated by the international mobility assessed by the number of foreign visited countries is important, the mean value were 1.19 , differenti- ated for male students 1.34 and girls 1.06 .

\subsection{General Eating Habits}

The general eating habits of investigated sample were presented in Table 3 and the gender differences in Tables 4 and 5.

The mean number of daily meals is 3.88 (SD is 1.30), including snack meals. The mean number of snack meal is 2.79 (1.68 snack meal at school), significant parts of the daily food intake were represented by rapid meal in the school break times which replace the principal meal of the day. The mean hour of last meal is 20.47 , late in the night because students have a night life due to the academic program extended until 5-6 p.m. The habit of having meal in the university canteen is underdeveloped; the mean meals consumed were 6.22 /month, 1.55 meals/ week.

The level of socialization by having meal together is represented with the number of out meals per months which was modest 3.06 , slightly greater in boy's case 3.33 than in girl's case 2.79 .

The dramatically value of meals alone (in average 7.48 per total sample, much more $8.67 /$ week in boys case) is 
Table 3. Sample food and eating general habits.

\begin{tabular}{|c|c|c|c|c|c|}
\hline Characteristics & $\mathrm{N}$ & Min. & Max. & Mean & $\mathrm{SD}$ \\
\hline Meals per day & 376 & 1 & 10 & 3.88 & 1.30 \\
\hline Snacks meal per day & 376 & 0 & 20 & 2.79 & 2.24 \\
\hline Hour of last meal & 376 & 16 & 24 & 20.47 & 1.99 \\
\hline Coffee consummation (ml) & 376 & 0 & 500 & 53.23 & 77.47 \\
\hline Red meat consummation(g/day) & 376 & 0 & 500 & 132.84 & 107.41 \\
\hline White meat consummation(g/day) & 376 & 0 & 1000 & 171.39 & 101.00 \\
\hline Fish consummation (g/day) & 376 & 0 & 500 & 106.05 & 99 \\
\hline Vegetable consummation (g/day) & 376 & 0 & 1500 & 331.01 & 225.24 \\
\hline Canteen meals per month & 376 & 0 & 60 & 6.22 & 8.35 \\
\hline Snack meals at school & 376 & 0 & 20 & 1.68 & 1.59 \\
\hline Breakfast duration(min.) & 376 & 0 & 120 & 11.32 & 9.61 \\
\hline Lunch extent (min.) & 376 & 0 & 100 & 20 & 10.64 \\
\hline Dinner extent (min.) & 376 & 0 & 100 & 21 & 11.60 \\
\hline Out meals per month & 376 & 0 & 30 & 3.06 & 2.90 \\
\hline Meal alone & 376 & 0 & 90 & 7.48 & 8.33 \\
\hline
\end{tabular}

Table 4. Male group sample food and eating general habits.

\begin{tabular}{|c|c|c|c|c|c|}
\hline Characteristics & $\mathrm{N}_{\mathrm{B}}$ & Min. & Max. & Mean & SD \\
\hline Meals per day & 177 & 2 & 10 & 4.04 & 1.49 \\
\hline Snacks meal per day & 177 & 0 & 20 & 2.81 & 2.25 \\
\hline Hour of last meal & 177 & 16 & 24 & 21.11 & 2.06 \\
\hline Coffee consummation (ml) & 177 & 0 & 500 & 58.70 & 82.37 \\
\hline Red meat consummation (g/day) & 177 & 0 & 500 & 168.64 & 109.55 \\
\hline White meat consummation (g/day) & 177 & 0 & 500 & 154.52 & 94.20 \\
\hline Vegetable consummation (g/day) & 177 & 0 & 1500 & 288.25 & 191.87 \\
\hline Canteen meals per month & 177 & 0 & 60 & 8.02 & 9.47 \\
\hline Snack meals at school & 177 & 0 & 15 & 1.76 & 1.57 \\
\hline Breakfast duration (min.) & 177 & 0 & 120 & 11.29 & 11.60 \\
\hline Lunch extent (min.) & 177 & 0 & 100 & 21.53 & 11.56 \\
\hline Dinner extent (min.) & 177 & 0 & 100 & 22.60 & 13.52 \\
\hline Out meal per month & 177 & 0 & 30 & 3.33 & 3.03 \\
\hline Self-cooked meals & 177 & 0 & 90 & 3.01 & 7.04 \\
\hline Meal alone & 177 & 0 & 90 & 8.67 & 9.85 \\
\hline
\end{tabular}

Table 5. Girl group sample food and eating general habits.

\begin{tabular}{|c|c|c|c|c|c|}
\hline Characteristics & $\mathrm{N}_{\mathrm{F}}$ & Min. & Max. & Mean & $\mathrm{SD}$ \\
\hline Meals per day & 199 & 1 & 6 & 3.75 & 1.10 \\
\hline Snacks meal per day & 199 & 0 & 20 & 2.75 & 2.24 \\
\hline Hour of last meal & 199 & 16 & 24 & 19.91 & 1.74 \\
\hline Coffee consummation (ml) & 199 & 0 & 500 & 48.09 & 72.56 \\
\hline Red meat consummation (g/day) & 199 & 0 & 500 & 100.33 & 94.89 \\
\hline White meat consummation (g/day) & 199 & 0 & 1000 & 185.78 & 104.85 \\
\hline Vegetable consummation (g/day) & 199 & 0 & 1000 & 368.39 & 245.26 \\
\hline Canteen meals per month & 199 & 0 & 50 & 4.63 & 6.82 \\
\hline Snack meals at school & 199 & 0 & 20 & 1.60 & 1.61 \\
\hline Breakfast duration (min.) & 199 & 0 & 30 & 11.31 & 7.42 \\
\hline Lunch extent (min.) & 199 & 0 & 60 & 18.47 & 9.57 \\
\hline Dinner extent (min.) & 199 & 0 & 60 & 18.98 & 9.27 \\
\hline Self-cooked meals & 199 & 0 & 20 & 3.59 & 3.39 \\
\hline Meal alone & 199 & 0 & 40 & 6.46 & 6.54 \\
\hline
\end{tabular}


an important sign of lack of satisfaction toward the actual commercial catering and canteen offer, associated with the reduced average spend power. The mean value of selfcooked meal sustain this conclusion, 3.59 meals per week were cooked by the girls and 3.01 by the male students.

The average consummation of healthy foods such fish is about $106.05 \mathrm{~g} /$ day, vegetables $331.01 \mathrm{~g} /$ day and white meat $171.39 \mathrm{~g} /$ day. The red meat is also preferred with a mean consummation of $132.84 \mathrm{~g} /$ day.

The extent of the principal meals is also an important lifestyle marker, the mean duration of the breakfast were $11.32 \mathrm{~min}$., lunch $20 \mathrm{~min}$. and dinner $21 \mathrm{~min}$.

\section{Discussion and Conclusions}

In the current study, more than three quarts of investigated sample $(76.06 \%)$ was of correct (normal) weight. Nearly $65.15 \%$ of the students reported having regular daily breakfast. This every day meal pattern is consistent with the traditional European three meals day model. The present results are also consistent with a study that reported that $84 \%$ of French students $62.2 \%$ of British students and $76 \%$ of all EU students had breakfast every day [4-8].

$6.38 \%$ of the students were underweight and a significant percentage (15.15\%) was found to be overweight. Contrary, in a Turkey study, $12.5 \%$ of students was found to be underweight and $6.2 \%$ overweight $[9,10]$.

In present study research, there was only one obese student, a boy (1/376). The prevalence of obesity reported here is in the range of $15 \%$ to $30 \%$ presented in a USA and Canada study conducted on children and adolescents [11-13].

The girls show a more tight body mass control because they attempt to attain the contemporary ideal of being thin and physically fit. The results are in line with [14], which reports that girls are more concerned about weight control and more motivated to adopt restrictive diets. The greatest influences in the present study were reported in family case $(47.35 \%)$ result confirmed by other recent studies [15-19].

In the present study, BMI values did not differ across gender groups in the normal-pondered weight range, but significant differences were reported in under and overweight cases. This result is compatible with a study carried out in Mexico showing that there was no important difference between girls' and boys' BMIs [2].

The values pattern of Romanian adolescents has dramatically changed during the last twenty years after the 1989 revolution, with preference toward static activities (television, moving, computer surfing) associated with fashionable and accessible fast food. The author perception is that the fast food culture is viewed as a "windows" toward the developed countries and an easy \& accessible way to escape from a society which give them a less valorisation, few motivations and no secure future. The illusion of being there, in a successful culture, gives the temptation to accessible and convenient fast food, which represents a strong symbol of occidental democratic values.

The charged academic program started in general at 8 a.m. and finished at 17 p.m. encourage snacking and in the absence of a resident canteen and meal break, there is no lunch. The breakfast is no more a fashionable habit and most of the students make no direct correlation between their academic performance and eating habits. The concern for the underweight is major for the girls and their daily eating menus are restricted and monotone. Because of the chaotic eating pattern, without fixed meals and well structured cycled menus, the prevalence of the underweight for the girls and obesity in boy's case is in an increasing trend and represent a sign of worries in the modern society.

\section{Acknowledgements}

The author is thankful to Irina Odagiu who carried out the field work.

\section{REFERENCES}

[1] L. L. Birch and J. O. Fisher, "Development of Eating Behaviours among Children and Adolescents," Pediatrics, Vol. 101, No. 3, 1998, pp. 539-549.

[2] M. E. P. Reyes, E. E. C. Barahona, M. B. Cahuim, A. Barragán and R. M. Malina, "Growth Status of Children 6 - 12 Years from Two Different Geographic Regions of Mexico," Annals of Human Biology, Vol. 29, No. 1, 2000, pp. 11-25. doi:10.1080/03014460110047964

[3] I. Vintilă and S. Chicos, "Science and Art in Catering," Didactical and Pedagogical Publishing House, Bucuresti, 2004.

[4] I. R. Contento, J. L. Michela and S. S. Williams, "Adolescent Food Choice Criteria: Role of Weight and Dieting Status," Appetite, Vol. 25, No. 1, 1995, pp. 51-76. doi:10.1006/appe.1995.0041

[5] J. K. Croll, D. Neumark-Sztainer and M. Story, "Healthy Eating: What Does It Mean to Adolescents?" Journal of Nutrition Education, Vol. 33, No. 4, 2001, pp. 193-198. doi:10.1016/S1499-4046(06)60031-6

[6] C. Klein-Platat, A. Wagner, M. C. Haan, D. Arveiler, J. L. Schlienger and C. Simon, "Prevalence and Sociodemographic Determinants of Overweight in Young French Adolescents," Diabetes/Metabolism Research and Reviews, Vol. 19, No. 2, 2003, pp. 153-158. doi:10.1002/dmrr.368

[7] M. O. Monneuse, F. Bellisle and G. Koppert, "Eating Habits, Food and Health Related Attitudes and Beliefs Reported by French Students," European Journal of Clinical Nutrition, Vol. 51, No. 1, 1997, pp. 46-53.

doi:10.1038/sj.ejen.1600361 
[8] D. Neumark-Sztainer, N. E. Sherwood, S. A. French and R. W. Jeffery, "Weight Control Behavior among Adult Men and Women: Cause for Concern?" Obesity Research, Vol. 7, No. 2, 1991, pp. 179-188. doi:10.1002/j.1550-8528.1999.tb00700.x

[9] Y.Coskun and Z. Bayraktaroglu, "Coronary Risk Factors in Turkish School Children-Report of a Pilot Study," Acta Pediatrica, Vol. 86, No. 2, 1997, pp. 187-191. doi:10.1111/j.1651-2227.1997.tb08866.x

[10] N. Erenoglu, U. Ayranci and O. Son, "Eating Habits Reported by Secondary School Students in a City of West Turkey," Eating Behaviour, Vol. 7, No. 4, 2006, pp. 348354. doi:10.1016/j.eatbeh.2005.11.009

[11] I. Janssen, P. T. Katzmarzyk, W. F. Boyce, M. A. King and W. Pickett, "Overweight and Obesity in Canadian Adolescents and Their Associations with Dietary Habits and Physical Activity Pattern," Journal of Adolescents Health, Vol. 35, No. 5, 2004, pp. 360-367.

[12] B. Rosner, R. Prineas, J. Loggie and S. R. Daniels, "Percentiles for Body Mass Index in US Children 5 to 17 Years of Age," Journal of Pediatrics, Vol. 132, No. 44, 1998, pp. 339-361.

[13] N. E. Sherwood, L. Harnack and M. Story, "Weight-Loss Practices, Nutrition Beliefs, and Weight-Loss Program Preferences of Urban American Indian Women," Journal of the American Dietetic Association, Vol. 100, No. 4,
2000, pp. 442-446. doi:10.1016/S0002-8223(00)00136-X

[14] L. M. Verbrugge, "Gender and Health: An Uptake on Hypotheses and Evidence," Journal of Health Behavioral Medicine, Vol. 26, No. 3, 1985, pp. 156-182. doi: $10.2307 / 2136750$

[15] J. Moore and N. Harre, "Eating and Activity: The Importance of Family and Environment," Health Promotion Journal of Australia, Vol. 18, No. 2, 2007, pp. 143-148.

[16] J. H. Pearson., S. J. H. Biddle and T. Gorely, "Family Correlate of Fruit and Vegetables Consummation in Children and Adolescents: A Systematic Review," Public Health Nutrition, Vol. 18, No. 8, 2008, pp. 1-17.

[17] M. Story, D. Neumark-Sztainer and S. A. French, "Individual and Environmental Influences on Adolescent Eating Behaviours," Journal of the American Dietetic Association, Vol. 102, No. 3, 2000, pp. S40-S51. doi:10.1016/S0002-8223(02)90421-9

[18] I. Vintilă, "Societal Influences and Health \& Emotional Impact of Food Behaviour \& Lifestyle in a Romanian High School Population of Teenagers," Review of Research and Social Intervention, Vol. 37, No. 6, 2012, pp. 130-143.

[19] D. E. Wilfrey and J. Rodin, "Cultural Influences on Eating Disorders: Eating Disorders and Obesity," Guilford Press, New York, 1995. 